\title{
Cervical cancer mortality by neighbourhood income in urban Canada from 1971 to 1996
}

\section{Edward Ng, Russell Wilkins, Michael Fung Kee Fung, Jean-Marie Berthelot}

Abstract

Background: The reduction of socioeconomic inequalities in health is an explicit objective of health policy in Canada, yet rates of death from cervical cancer are known to be higher among women of low socioeconomic status than among those of higher socioeconomic status. To evaluate progress toward the World Health Organization's goal of "Health for All," we examined whether income-related differentials in cervical cancer mortality diminished from 1971 to 1996.

Methods: Death registration data for Canada's census metropolitan areas in 1971, 1986, 1991 and 1996 were assigned to census tracts through postal code, and the tracts were in turn assigned to income quintiles based on their proportion of the population below the Statistics Canada low-income cutoff values. We compared age-standardized death rates (using the 1966 world population standard) in the female population (excluding those in institutions) across the 5 income quintiles and calculated interquintile rate ratios (poorest over richest) and interquintile rate differences (poorest minus richest).

Results: From 1971 to 1996, the overall age-standardized cervical cancer death rate per 100000 women (and 95\% confidence interval) declined from $5.0(4.5-5.6)$ to $1.9(1.7-2.1)$, the interquintile rate ratio diminished from $2.7(1.8-4.2)$ to 1.7 (1.1$2.6)$, and the interquintile rate difference decreased from 4.6 (2.8-6.4) to $1.1(0.2-1.9)$.

Interpretation: The income-related disparity in rates of death from cervical cancer as measured by rate ratios and rate differences diminished markedly in urban Canada from 1971 to 1996. Among the numerous factors that may have contributed to the decline (including decline in fertility and improvement in diet), one important factor was probably the implementation of effective screening programs.

CMAJ 2004;170(10):1545-9

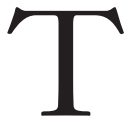

he 1995 Canadian National Forum on Cervical Cancer Screening asserted: "In a perfect world, there ought not to be any deaths due to cervical cancer." Since cervical cancers are detectable and treatable at an early stage, most deaths from this disease are avoidable. ${ }^{2}$ In 2000 an estimated 1450 women in Canada received the diagnosis of cervical cancer, and an estimated 430 women died from the disease in the same year. Of all cancers among women, cervical cancer had the 12th highest incidence and the 14th highest death rate. ${ }^{3}$
The purpose of this study was to examine trends in rates of death from cervical cancer by neighbourhood income in urban Canada from 1971 to 1996 , and to determine whether income-related differentials in mortality have diminished as expected since publicly funded universal health insurance was introduced in Canada, in the early 1970s. The reduction of socioeconomic inequities in health is an important aspect of population health, which aims to "reduce inequities in the underlying conditions that put some Canadians at a disadvantage for attaining and maintaining optimal health." ${ }^{4}$ In addition, we compared Canadian data on cervical cancer incidence and mortality with those for the body of the uterus, and compared trends in cervical cancer death rates for selected countries.

\section{Methods}

The methods of studies of mortality by neighbourhood income have been described in detail elsewhere. ${ }^{5}$ In brief, death registrations for residents of Canadian census metropolitan areas (excluding those in institutions) in census years 1971, 1986, 1991 and 1996 were assigned to census tracts, based on the postal code or address of the deceased's usual place of residence. Because data on deaths for 1976 and 1981 were not coded to census tract, we did not include those years in the current analysis. The underlying cause of death had previously been coded to the ICD-8 (International Classification of Diseases, 8th revision ${ }^{6}$ ) for deaths in 1971 and to the ICD-9 (9th revision ${ }^{7}$ ) for deaths in 1986, 1991 and 1996. Within each census metropolitan area, the census population in census tracts was grouped into neighbourhood income quintiles based on the proportion of the population in the census tract below the Statistics Canada low-income cutoff values at that time. Deaths were then assigned to those quintiles. In this study, Q1 represents the richest quintile and Q5, the poorest.

For each study year and quintile we calculated the agestandardized rate of death from cervical cancer (ICD-8 and ICD9 code 180) using the 1966 world population standard. Incomerelated differentials in mortality were summarized in terms of interquintile rate ratios (Q5/Q1) and interquintile rate differences (Q5 - Q1). We calculated excess deaths as the number of deaths observed less the number of deaths expected if all quintiles had experienced the age-specific death rates of the richest quintile. We calculated standard errors for the age-standardized death rates as described by Spiegelman, ${ }^{8}$ who assumes a binomial distribution of the rates in each age stratum. We calculated $95 \%$ confidence intervals (CIs) for the age-standardized death rates, rate 
ratios and rate differences from the standard errors of the agestandardized death rates, assuming that the log of the death rate, the $\log$ of the rate ratio and the rate difference are normally distributed. We calculated 95\% CIs for excess deaths assuming a Poisson distribution of the deaths in each age group and a normal distribution of the excess.

We compared trends in cervical cancer mortality from 1971 to 1996 for countries with historically close connections with Canada (United States, United Kingdom and France) plus Nordic countries with the highest and lowest rates (Norway and Finland) using 3-year moving averages based on data from the International Association for Research on Cancer, age-standardized to the 1966 world population. ${ }^{9}$

For Canadian women as a whole (not by quintile), we obtained annual cancer incidence and death rates for 1971-2002 (estimated for 1999-2002), age-standardized to the 1991 Canadian population, from Canadian Cancer Statistics. ${ }^{3,10} \mathrm{We}$ compared rates for cervical cancer with the corresponding rates for cancer of the body of the uterus (ICD-8 and ICD-9 code 182).

\section{Results}

\section{Canadian incidence and mortality trends}

Based on the 1991 Canada population standard, the age-standardized rate of death from cervical cancer per 100000 women was 6.9 in 1971 and declined by $71 \%$ in 2002, to 2.0 (Fig. 1). In contrast, the age-standardized rate of death from cancer of the body of the uterus per 100000 women was 5.1 in 1971 and 3.1 in 2002, a decrease of $39 \%$. The crossover in death rates for the 2 types of cancer occurred in 1979, following a period of much more rapid decline in cervical cancer mortality in the early 1970s.

The age-standardized incidence of cervical cancer per 100000 women fell from 19.4 in 1971 to 7.8 in 2002, a

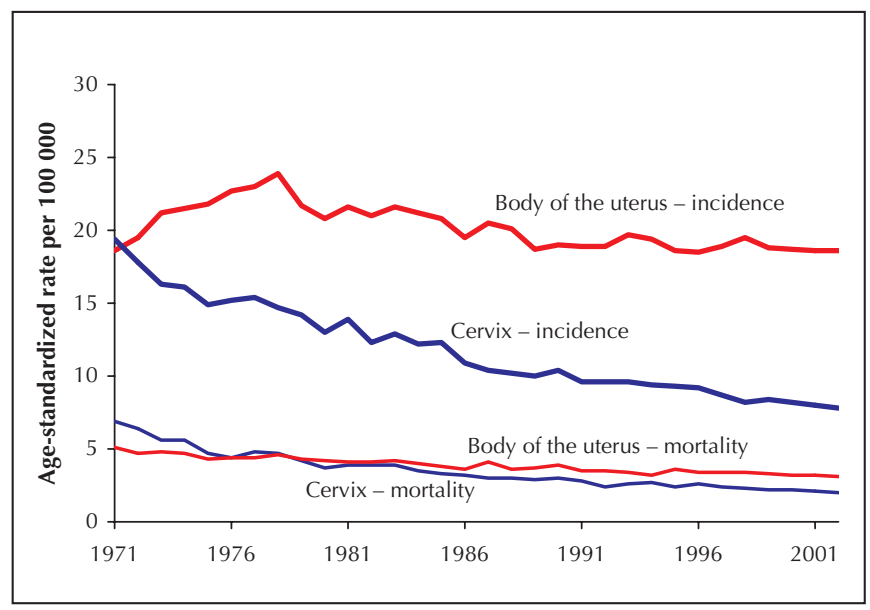

Fig. 1: Age-standardized incidence and death rates per 100000 women in Canada for cancers of the cervix and body of the uterus from 1971 to 2001. Note: Age-standardized to the 1991 Canadian population. Data for 1999-2002 are estimated. Source: National Cancer Institute of Canada.,10 decrease of $60 \%$ (Fig. 1). The incidence of cancer of the body of the uterus was 18.6 in 1971. It increased to a peak of 23.9 in 1978 and then gradually fell back to about the 1971 level by 1989, after which it remained essentially stable.

\section{International comparisons}

The age-standardized rates of death from cervical cancer per 100000 women (based on the 1966 world population standard) for Canada and 5 other developed countries are shown in Fig. 2. For Canada, the rate was 5.4 in 1971 and 1.9 in 1995, a decrease of $65 \%$. In contrast, the initially high rates for the United Kingdom and Norway declined by $50 \%$ and $46 \%$ respectively, the initially low rate for France decreased by $42 \%$, and the initially moderate rate for Finland declined by $74 \%$, the rate for this country falling below that for France in 1986. The United States had a slightly lower rate than Canada had in 1971, and the rates in the 2 countries declined roughly in parallel until 1983, after which the decline stalled in the United States but continued in Canada, so that by 1996 the rate for the United States was 26\% higher than that for Canada.

\section{Cervical cancer mortality by income}

The decrease in the age-standardized rate of death from cervical cancer in urban Canada from 1971 to 1996 (Table 1) was similar to that for all Canada shown in Fig. 1 (but note the change from 1991 Canada population standard in Fig. 1 to 1966 world population standard in Table 1 and elsewhere). The age-standardized death rate in urban Canada fell from 5.0 (95\% CI 4.5-5.6) in 1971 to 1.9 (95\% CI 1.7-2.1) in 1996, a decline of $62 \%$.

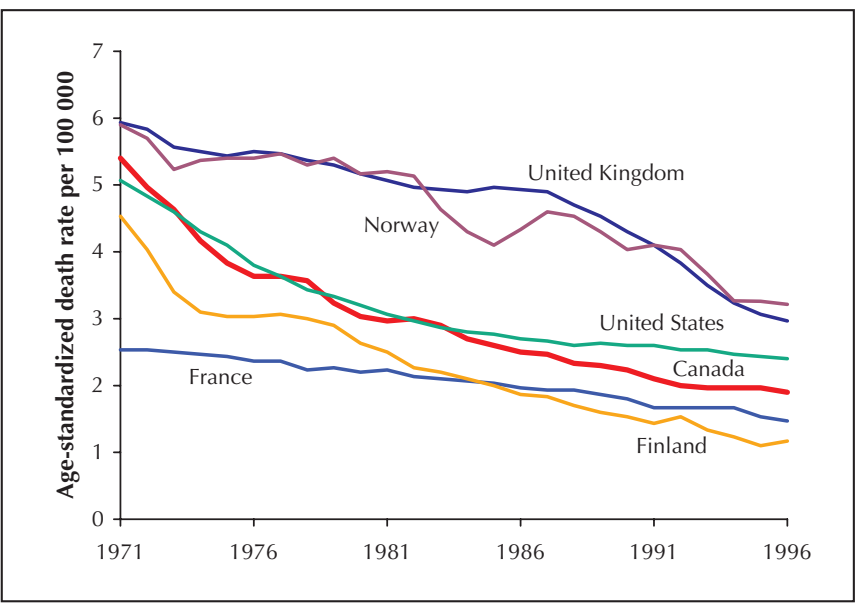

Fig. 2: Age-standardized cervical cancer death rates per 100000 women in Canada and selected other countries from 1971 to 1996 (3-year moving averages). Note: Age-standardized to the 1966 world population. Source: International Association of Cancer Registries. ${ }^{9}$ 
Cervical cancer mortality displayed a very strong income gradient in 1971, but the gradient diminished quite markedly over the study period (Fig. 3). In the poorest quintile the age-standardized death rate per 100000 women fell from 7.2 (95\% CI 6.0-8.9) in 1971 to 2.5 (95\% CI 1.9-3.3) in 1996, a decrease of $65 \%$, whereas in the richest quintile the rate declined from 2.7 (95\% CI $1.8-3.9$ ) in 1971 to 1.5 (95\% CI 1.1-2.1) in 1996, a decrease of $44 \%$. Considerable rate reductions were observed in all income quintiles from 1971 to 1986 , but from 1986 to 1996 the 3 richest quintiles experienced no further reductions, whereas rates in the 2 poorest quintiles continued to decline.

The interquintile rate difference narrowed from 4.6 (95\% CI 2.8-6.4) in 1971 to 1.1 (95\% CI 0.2-1.9) in 1996, a decrease of $76 \%$ (Table 1). The interquintile rate ratio decreased from 2.7 (95\% CI 1.8-4.2) in 1971 to 1.7 (95\% CI 1.1-2.6) in 1996, a decline of $37 \%$. The number of income-related excess deaths due to cervical cancer fell from 154 (95\% CI $118-190)$ in 1971 to 50 (95\% CI 18-81) in 1996 , a decrease of $68 \%$.

\section{Interpretation}

For Canada as a whole, the most rapid reductions in cervical cancer mortality were achieved in the years immediately following the introduction of publicly funded universal health insurance, in the early 1970s. For neighbourhood income quintiles in urban Canada, because of the lack of data points for 1976 and 1981, we cannot know exactly when during the period 1971-1986 the rates declined most rapidly. However, it is clear that the rates for the poorer quintiles declined much more than did those for the richer quintiles. Cervical cancer incidence also declined substantially over the full 25-year period 1971-1996, but corresponding incidence data by socioeconomic category were not available to help us better understand the dynamics of these diminishing disparities in mortality.

Among the numerous factors that may have contrib- uted to the decline in cervical cancer mortality in Canada, including improvement in diet and decline in fertility rates, is the increased use of the Papanicolaou test, which allows detection of precancerous lesions through visualization of cellular abnormalities..$^{2,3,11-15}$ Nevertheless, past studies have consistently shown important socioeconomic differentials in Papanicolaou test use in Canada during the 1980s and 1990s, ${ }^{16-23}$ despite universal health care coverage, which presumably facilitated the opportunistic use of the test by removing financial barriers. These differentials persisted even after adjustment for hysterectomy status. ${ }^{24}$

By 1996, the rate of death from cervical cancer in Canada had fallen close to the level prevailing about a decade earlier in Finland (where organized Papanicolaou screening programs started in the 1960s) and in France, and far below those of Norway (where organized screening did not materialize) 25,26 and the United Kingdom (where cervical screening started in 1964 but failed to achieve sufficient coverage or follow-up). ${ }^{27}$ In France, where the rate of death from cervical cancer was low even in 1971, opportunistic screening has been more widespread, resulting in a continuing gradual decline in the rates. ${ }^{28}$

The United States experienced a decline in cervical cancer mortality similar to that of Canada in the 1970s and early 1980s, but the decline in that country seems to have stalled from the mid-1980s onward, resulting in a growing divergence in the rates for the 2 countries. The exact reason for this divergence is unclear but may be partly attributable to differential access to preventive health care services, since there were substantial changes in health insurance coverage and in the use of preventive health care in the United States over this period. For example, the age-adjusted proportion of the population under 65 years of age without coverage rose from $12.5 \%$ in 1980 to $17.2 \%$ in $1992 .{ }^{29}$ The growing divergence in death rates may also be due to differential survival by socioeconomic status: in a 1997 study, survival following diagnosis of cervical cancer was associated with neighbourhood income in Detroit but not in Toronto. ${ }^{30}$

\begin{tabular}{|c|c|c|c|c|}
\hline \multirow[b]{2}{*}{ Variable } & \multicolumn{4}{|c|}{ Year } \\
\hline & 1971 & 1986 & 1991 & 1996 \\
\hline No. of deaths & 329 & 237 & 251 & 247 \\
\hline $\begin{array}{l}\text { Age-standardized death rate } \\
\text { per } 100000 \text { women (and } 95 \% \mathrm{Cl} \text { ) }\end{array}$ & $5.0(4.5-5.6)$ & $2.4(2.2-2.8)$ & $2.2(1.9-2.5)$ & $1.9(1.7-2.1)$ \\
\hline Rate ratio (Q5/Q1) (and 95\% Cl) & $2.7(1.8-4.2)$ & $2.8(1.7-4.6)$ & $2.3(1.5-3.5)$ & $1.7(1.1-2.6)$ \\
\hline Rate difference (Q5 - Q1) (and 95\% Cl) & $4.6(2.8-6.4)$ & $2.6(1.5-3.7)$ & $2.0(1.0-3.0)$ & $1.1(0.2-1.9)$ \\
\hline $\begin{array}{l}\text { No. of income-related excess deaths } \\
\text { (and } 95 \% \mathrm{Cl} \text { ) }\end{array}$ & $154(118-190)$ & $106(75-137)$ & $83(51-115)$ & $50(18-81)$ \\
\hline
\end{tabular}

Note: $\mathrm{Cl}$ = confidence interval; $\mathrm{Q} 1$ = richest quintile; Q5 = poorest quintile

*Age-standardized to the 1966 world population.

Source: Statistics Canada Canadian Mortality Data Base and supplemental files; special tabulations of census population data. 
Persistent socioeconomic inequalities in cervical cancer mortality have been noted in the United States from 1975 to $1999,{ }^{31}$ in contrast to the diminishing disparity we found in Canada.

Limitations to a study of mortality by neighbourhood income have been described elsewhere. ${ }^{5}$ We studied only residents of census metropolitan areas, which account for some $60 \%$ of Canada's total population. The fact that smaller urban and rural areas were not studied may hide inequities in disease burden among rural and small town populations, including Aboriginal populations. As well, the study was based on neighbourhood income rather than on family or individual income; however, other Canadian studies suggest that the pattern of socioeconomic disparities in mortality found in our study is a reasonable reflection of what might be expected at the individual level..$^{32,33}$ Finally, we did not include ICD code 179 (cancer of the uterus, site unspecified) in the analysis. Some deaths from cervical cancer may have been misclassified to that code. If so, the effect would have been for us to underestimate the true extent of the reduction of socioeconomic inequalities in cervical cancer mortality, since our unpublished data (2003) show that age-standardized death rates for code 179 declined more pronouncedly in the poorest quintile than in the richer quintiles.

With respect to the goal of "Health for All," ${ }^{34}$ the reduction in income-related disparities in cervical cancer mortality in urban Canada is a success story. However, as Canada's rates are still far higher than those of France and especially Finland, there is clearly room for improvement.
Many authors have advocated screening that targets the population that is at high risk and generally disadvantaged. ${ }^{12,13,35,36}$ However, our data show that the cervical cancer death rates among women in the 3 richest income quintiles ceased declining in 1986, whereas rates for the 2 poorest quintiles have continued to decline. Thus, what may be needed is a truly organized and systematic population-based screening program. The understanding of a necessary but not sufficient causal relation between human papilloma virus (HPV) and cervical cancer, recent advances in screening techniques (HPV testing at the molecular level and liquid-based cytology) and the possibility that cancer of the cervix may now be preventable by vaccination against HPV infection may also help reduce rates of death from cervical cancer. ${ }^{37-41}$ Together, these measures offer hope for further reduction in cervical cancer mortality for all women in Canada.

\section{This article has been peer reviewed.}

From the Health Analysis and Measurement Group, Statistics Canada, Ottawa, Ont. (Ng, Wilkins, Berthelot); the Department of Epidemiology and Community Medicine (Wilkins) and the Gynaecologic Oncology Programme, Faculty of Medicine, University of Ottawa, Ottawa, Ont. (Fung Kee Fung); and the Department of Epidemiology and Biostatistics, McGill University, Montréal, Que. (Berthelot)

Competing interests: None declared.

Contributors: Russell Wilkins designed the study and revised successive versions of the manuscript. Edward Ng performed the analysis and drafted the article. JeanMarie Berthelot contributed substantially to data acquisition and provided feedback at various stages of the analysis and writing of the manuscript. Michael Fung Kee Fung provided specialist medical expertise on various aspects of interpretation of the results. All authors participated in the development of the manuscript and gave approval to its final submission for publication.

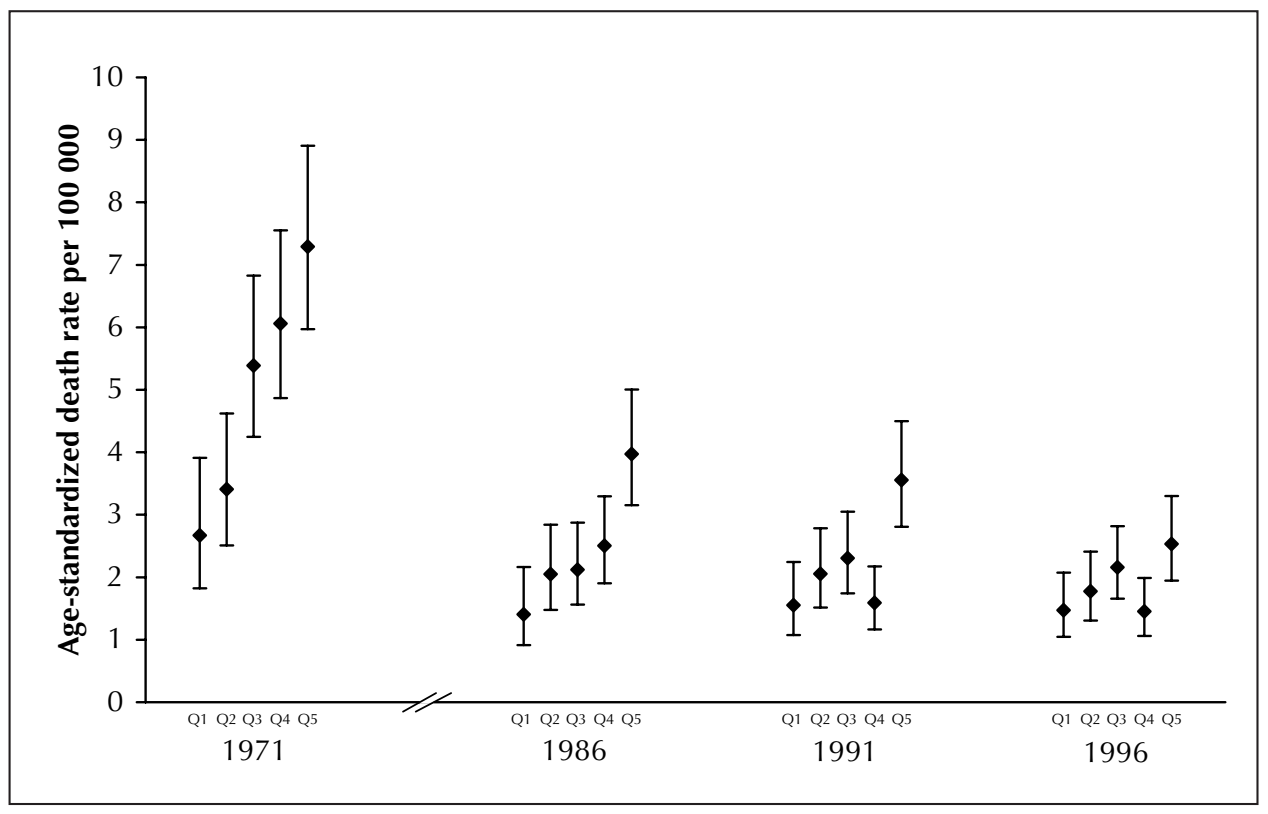

Fig. 3: Age-standardized cervical cancer death rates (and 95\% confidence intervals) per 100000 women in urban Canada by neighbourhood income quintile from 1971 to 1996. Q1 = richest quintile, Q5 = poorest quintile. Note: Age-standardized to the 1966 world population. Source: Statistics Canada Canadian Mortality Data Base and supplemental address files; special tabulations of census population data. 


\section{References}

1. Health Canada. Proceedings of Interchange '95: a Canadian forum to collaborate on cervical cancer screening program implementation strategies. Ottawa: Health Canada; 1995. p. 7. Cat no H39-357/1995E

2. Health Canada. Cervical cancer screening in Canada: 1998 surveillance report. Ottawa: Health Canada; 2002. p. ix, 8. Cat no H39-616/1998E.

3. National Cancer Institute of Canada. Canadian cancer statistics 2000. Toronto: The Institute; 2000.

4. Federal, Provincial and Territorial Advisory Committee on Population Health. Toward a bealthy future: second report on the bealth of Canadians. Ottawa: The Committee; 1999. p. xv. Cat no H39-468/1999E.

5. Wilkins R, Berthelot JM, Ng E. Trends in mortality by neighbourhood income in urban Canada from 1971 to 1996. Health Rep 2002;13(Suppl):45-72.

6. International classification of diseases. 8th rev. Geneva: World Health Organization; 1969.

7. International classification of diseases. 9th rev. Geneva: World Health Organization; 1978.

8. Spiegelman M. Introduction to demography. Rev ed. Cambridge (MA): Harvard University Press; 1968. p. 111-4.

9. World Health Organization. The International Association of Cancer Registries cancer mortality database; 2001. Available: www-dep.iarc.fr/dataava/infodata .htm (accessed 2004 Feb 12).

10. National Cancer Institute of Canada. Canadian cancer statistics 2002. Toronto: The Institute; 2002.

11. Miller AB. Planning cancer control strategies. Chronic Dis Can 1992;13(1):S1-40.

12. Health Canada. Cervical cancer in Canada: March 1998 cancer updates. Ottawa: Health Canada Cancer Bureau; 1998. p. 4.

13. Miller $\mathrm{AB}$. The brave new world: What can we realistically expect to achieve through cancer control early in the new millennium? Chronic Dis Can 1999;20 (4):139-50.

14. Band PR, Gaudette LA, Hill GB, Holowaty EJ, Huchcroft SA, Johnston GM, et al. The making of the Canadian Cancer Registry: cancer incidence in Canada and its regions, 1969 to 1988. Ottawa: Minister of Supply and Services Canada; 1993. p. 52-3. Cat no C52-42/1992.

15. Gaudette LA, Altmayer CA, Wysocki M, Gao RN. Cancer incidence and mortality across Canada. Health Rep 1998;10(1):51-66.

16. Garceau S. Female preventive health practices. In: Rootman I, Warren R, Stephens T, Peters L, editors. Canada's Health Promotion Survey: technical report. Ottawa: Department of National Health and Welfare / Minister of Supply and Services Canada; 1988. p. 79-88. Cat no H39-119/1988E.

17. O'Connor A. Women's cancer prevention practices. In: Stephens T, Graham DF, editors. Canada's Health Promotion Survey 1990: technical report. Ottawa: Department of National Health and Welfare / Minister of Supply and Services Canada; 1993. p. 169-80. Cat no H39-263/2-1990E.

18. Lee J, Parsons GF, Gentleman JF. Falling short of Pap test guidelines. Health Rep 1998;10(1):9-19.

19. Snider J, Beauvais J, Levy I, Villeneuve P, Pennock J. Trends in mammography and Pap smear utilization in Canada. Chronic Dis Can 1998;17(3-4):108-17.

20. Katz SJ, Hofer TP. Socioeconomic disparities in preventive care persist despite universal coverage. Breast and cervical cancer screening in Ontario and the United States. FAMA 1994;272(7):530-4

21. Goel V. Factors associated with cervical cancer screening: results from the Ontario Health Survey. Can 7 Public Health 1994;85(2):125-7.

22. Maxwell CJ, Bancej CM, Snider J, Vik SA. Factors important in promoting cervical cancer screening among Canadian women: findings from the 1996-97 National Population Health Survey (NPHS). Can 7 Public Health 2001;92(2):127-33.

23. Gupta S, Roos LL, Walld R, Traverse D, Dahl M. Delivering equitable care: comparing preventive services in Manitoba. Am f Public Health 2003;93:2086-92.

24. Snider JA, Beauvais JE. Pap smear utilization in Canada: estimates after ad- justing the eligible population for hysterectomy status. Chronic Dis Can 1998 19(1):19-24

25. Anttila A, Nieminen P. Cervical cancer screening programme in Finland. Eur 7 Cancer 2000;36(17):2209-14.

26. Sigurdsson K. The Icelandic and Nordic cervical screening programs: trends in incidence and mortality rates through 1995. Acta Obstet Gynecol Scand 1999; 78(6):478-85.

27. Quinn M, Babb P, Jones J, Allen E. Effect of screening on incidence of and mortality from cancer of cervix in England: evaluation based on routinely collected statistics. BM7 1999;318:904-8.

28. Schaffer P, Sancho-Garnier H, Fender M, Dellenbach P, Carbillet JP, Monnet E, et al. Cervical cancer screening in France. Eur 7 Cancer 2000;36(17) 2215-20.

29. Makuc DM, Fried VM, Parsons PE. Health insurance and cancer screening among women. Adv Data 1994;(254):1-2.

30. Gorey KM, Holowaty EJ, Fehringer G, Laukkanen E, Moskowitz A, Webster DJ, et al. An international comparison of cancer survival: Toronto, Ontario, and Detroit, Michigan, metropolitan areas. Am 7 Public Health 1997;87(7): 1156-63.

31. Singh GK, Millar BA, Hankey BF, Edwards BK. Area socioeconomic variations in U.S. cancer incidence, mortality, stage, treatment, and survival, 1975-1999. NCI Cancer Surveillance Monograph ser no 4. Bethesda (MD): National Cancer Institute, National Institutes of Health, US Department of Health and Human Services; 2003. NIH publication no 03-5417.

32. Veugelers PJ, Yip AM, Kephart G. Proximate and contextual socioeconomic determinants of mortality: multilevel approaches in a setting with universal health care coverage. Am 7 Epidemiol 2001;154(8):725-32.

33. Mustard CA, Derksen S, Berthelot JM, Wolfson M. Assessing ecologic proxies for household income: a comparison of household and neighbourhood level income measures in the study of population health status. Health Place 1999;5:157-71.

34. World Health Organization. Targets for bealth for all. Copenhagen: World Health Organization Regional Office for Europe; 1985.

35. Luciani S, Berman NJ. Status report: Canadian strategy for cancer control Chronic Dis Can 2000;21(1):23-5.

36. Lipskie T, Gibbons L, Whylie B, Bryant H, Ashbury FD. Knowledge, attitudes and behaviours concerning cancer screening in Canada. Chronic Dis Can 1997;18(4):176-8.

37. Bosch FX, Lorincz A, Muñoz N, Meijer CJL, Shah KV. The causal relation between human papillomavirus and cervical cancer. 7 Clin Pathol 2002;55(4):244-65.

38. Sherman ME, Schiffman M, Cox JT. Atypical Squamous Cells of Undetermined Significance/Low-Grade Squamous Intraepithelial Lesion Triage Study Group. Effects of age and human papilloma viral load on colposcopy triage: data from the randomized Atypical Squamous Cells of Undetermined Significance/Low-Grade Squamous Intraepithelial Lesion Triage Study (ALTS). 7 Natl Cancer Inst 2002;94(2):102-7.

39. Wright TC Jr, Cox JT, Massad LS, Twiggs LB, Wilkinson EJ; ASCCP Sponsored Consensus Conference. 2001 Consensus Guidelines for the management of women with cervical cytological abnormalities. 7AMA 2002;287 (16):2120-9.

40. Koutsky LA, Ault KA, Wheeler CM, Brown DR, Barr E, Alvarez FB, et al. A controlled trial of a human papillomavirus type 16 vaccine. $N$ Engl $7 \mathrm{Med}$ 2002;347(21):1645-51.

41. Crum CP. The beginning of the end for cervical cancer? N Engl F Med 2002; 347(21):1703-6.

Correspondence to: Russell Wilkins, Health Analysis and Measurement Group, Statistics Canada RHC-24A, Ottawa ON K1A 0T6; fax 613 951-3959; wilkrus@statcan.ca 